Results: Of 13,491 patients followed-up in RABBIT, 2274 with an age $>70$ years were included in the analysis. $626 \mathrm{SI}$ were observed in 425 of these patients. Baseline characteristics at start of the respective DMARD are shown in Table 1. In most characteristics, patients on JAKi were more comparable to patients under bDMARDs than to those on csDMARDs. JAKi patients received glucocorticoids (GC) less frequently than patients on other treatments. The HR for SI was lower than 1 in patients receiving bDMARDs or JAKi compared to csDMARDs, but without statistical significance (Figure 1). GC use (HR 1.6, 95\% Cl: $1.2-2.2$ for $\leq 10 \mathrm{mg} / \mathrm{d}$ ), higher DAS28-ESR values (HR 1.1, 95\% Cl: $1.0-1.2$ per 1 point increase), COPD or pulmonary fibrosis (HR 1. 8, 95\% Cl: $1.3-2.4)$, chronic kidney disease (HR 1.5, 95\% Cl: 1.2 - 1.9) and diabetes mellitus (HR 1.3, 95\% Cl: $1.0-1.7)$ were associated with an increased risk of SI. Better physical capacity was associated with a decreased risk of SI (HR 0.9, 95\% Cl: $0.88-0.98$ for a 10 point increase).

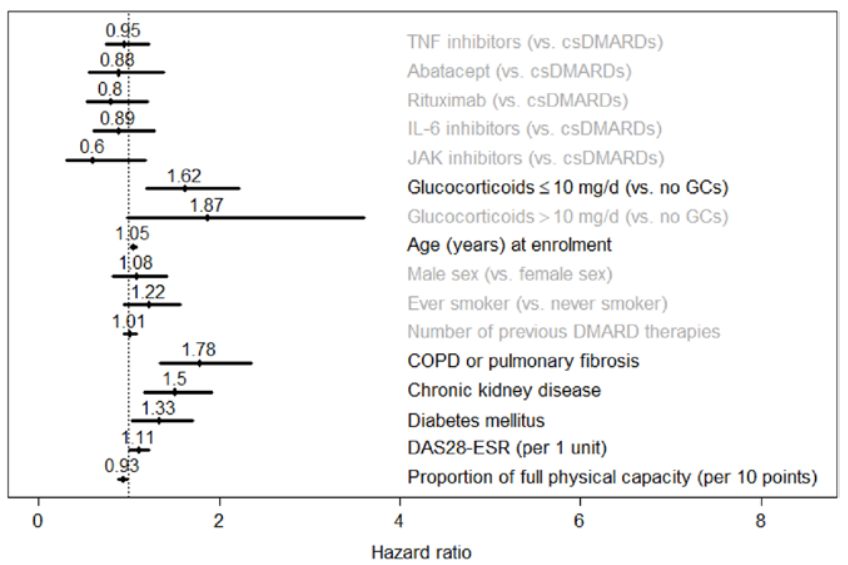

Figure 1. Hazard ratios for serious infections with $95 \%$ confidence intervals

Conclusion: Treatment with JAKi as well as treatment with bDMARDs was not associated with an increased risk of $\mathrm{SI}$ in elderly patients above 70 years of age. Key comorbidities such as diabetes mellitus, chronic pulmonary and kidney diseases were associated with increased risk, as was concomitant GC use and higher disease activity.

REFERENCES:

[1] Listing J et al., Rheumatology 2013; 52 (1): 53-61.

[2] Kawashima H. et al., Rheum. Intern. 2017; 37: 369-376.

Acknowledgements: RABBIT is supported by a joint, unconditional grant from AbbVie, Amgen, BMS, Celltrion, Fresenius-Kabi, Gilead, Hexal, Lilly, MSD, Pfizer, Roche, Samsung Bioepis, Sanofi-Aventis, UCB, and Viatris.

Table 1. Patient characteristics by treatment at baseline

\begin{tabular}{|c|c|c|c|c|c|c|}
\hline Parameter & csDMARDs & TNFi & RTX & ABA & IL-6i & JAKi \\
\hline & $N=758$ & $\mathrm{~N}=840$ & $\mathrm{~N}=\mathbf{2 0 9}$ & $\mathrm{N}=147$ & $\mathrm{~N}=\mathbf{2 1 2}$ & $\mathrm{N}=108$ \\
\hline Age (years) & 75.9 (3.9) & $75.5(3.6)$ & $74.8(3.6)$ & $76.1(3.9)$ & $75.9(3.7)$ & $76.7(3.7)$ \\
\hline Male sex & $184(24.3)$ & $220(26.2)$ & $50(23.9)$ & $36(24.5)$ & $46(21.7)$ & $28(25.9)$ \\
\hline Ever smoker & 249 (32.8) & $287(34.2)$ & 77 (36.8) & $50(34)$ & $73(34.4)$ & $39(36.1)$ \\
\hline $\begin{array}{l}\text { Disease duration } \\
\text { (years) }\end{array}$ & $7.9(8.8)$ & $12.3(11.4)$ & $17(11.1)$ & $12.8(10)$ & $13.8(11.7)$ & $11.9(10.9)$ \\
\hline Seropositivity & $487(64.3)$ & $671(79.9)$ & 201 (96.2) & $126(85.4)$ & $182(85.8)$ & 79 (73.5) \\
\hline $\begin{array}{l}\text { Number of previous } \\
\text { DMARDs }\end{array}$ & $1.4(0.7)$ & $2.5(1.3)$ & $4.2(1.8)$ & $3.6(1.9)$ & $3.3(1.8)$ & $2.6(1.5)$ \\
\hline DAS28-ESR & $4.6(1.2)$ & $5.1(1.2)$ & $5.4(1.3)$ & $5.3(1.3)$ & $5.3(1.3)$ & $5(1.2)$ \\
\hline $\begin{array}{l}\text { Proportion of full } \\
\text { physical function }\end{array}$ & $64.8(23.1)$ & $57.1(23.6)$ & $50.4(23.7)$ & $52.9(23.5)$ & $55.3(24.1)$ & $55.2(23.7)$ \\
\hline $\begin{array}{l}\text { Number of } \\
\text { comorbidities }\end{array}$ & $3.1(2.5)$ & $3.8(2.6)$ & $4.2(2.6)$ & $4.6(2.9)$ & $3.6(2.4)$ & $3.8(2.2)$ \\
\hline No comorbidity & $52(6.9)$ & $29(3.5)$ & $4(1.9)$ & $4(2$ & & $5(4.6)$ \\
\hline $\begin{array}{r}\text { Three and more } \\
\text { comorbidities }\end{array}$ & $385(50.8)$ & $528(62.9)$ & $147(70.3)$ & $107(72.8)$ & $131(61.8)$ & $76(70.4)$ \\
\hline $\begin{array}{l}\text { COPD or pulmonary } \\
\text { fibrosis }\end{array}$ & $69(9.1)$ & $89(10.6)$ & $29(13.9)$ & $26(17.7)$ & $12(5.7)$ & $11(10.2)$ \\
\hline Chronic kidney disease & $94(12.4)$ & $151(18)$ & $28(13.4)$ & $21(14.3)$ & 39 (18.4) & $22(20.4)$ \\
\hline Diabetes mellitus & $151(19.9)$ & $172(20.5)$ & $31(14.8)$ & $23(15.6)$ & $42(19.8)$ & 25 (23.1) \\
\hline GCs (last 6 months) & $347(45.8)$ & $526(62.6)$ & $143(68.8)$ & $82(56.2)$ & $127(59.9)$ & $44(40.7)$ \\
\hline GCs $(<5 \mathrm{mg})$ & 447 (58.9) & $384(45.7)$ & $101(48.2)$ & $88(60)$ & $118(55.8)$ & $72(66.7)$ \\
\hline GCs (5-9mg) & $252(33.3)$ & $375(44.6)$ & $81(38.7)$ & $43(29)$ & $72(34.2)$ & $27(25.1)$ \\
\hline GCs $(>=10 \mathrm{mg})$ & $59(7.8)$ & $82(9.8)$ & $274(13.1)$ & $16(11)$ & $21(10)$ & $9(8.2)$ \\
\hline
\end{tabular}

Results are presented as mean \pm SD for continuous variables and number (percentage) for discrete variables.
Disclosure of Interests: None declared

DOI: 10.1136/annrheumdis-2021-eular.763

\section{OP0117 REAL-WORLD EFFECTIVENESS OF TNFI VERSUS NON-TNFI BIOLOGICS ON DISEASE ACTIVITY IN PATIENTS WITH RHEUMATOID ARTHRITIS: DATA FROM THE ACR'S RISE REGISTRY}

M. Gianfrancesco ${ }^{1}$, J. LI ${ }^{1}$, M. Evans ${ }^{1}$, M. Petersen ${ }^{2}$, G. Schmajuk ${ }^{1}$, J. Yazdany ${ }^{1}$. ${ }^{1}$ University of California, San Francisco, Medicine, San Francisco, United States of America; ${ }^{2}$ University of California, Berkeley, Biostatistics, San Francisco, United States of America

Background: Our understanding of how medications such as biologic disease modifying anti-rheumatic drugs and targeted small molecules (b/tsDMARDs) influence disease activity in RA is based largely on randomized controlled trials (RCTs). However, most U.S. trials in RA are limited by small sample sizes and have often excluded patients who are older, male, and from racial/ethnic minorities. Whether effectiveness of b/tsDMARDs varies in these populations has largely been unexplored.

Objectives: We aimed to examine differences in longitudinal RA disease activity by demographic and clinical characteristics using a novel electronic health record data source of rheumatology providers across the U.S. We simulated various treatment assignments of b/tsDMARDs that have been examined in RCTs: namely, TNF-inhibitors (TNFi) and non-TNFi.

Methods: We included 16,448 individuals from the ACR's RISE registry with $\geq$ 2 RA diagnoses (ICD-9: 714.0) $\geq 30$ days apart, who had at least 2 recorded clinical disease activity index (CDAl) scores and no historical b/tsDMARD use documented in RISE. b/tsDMARD use and CDAl scores were assessed at each quarter; covariates included sex, race (white, Black, Asian, other), ethnicity (Hispanic/non-Hispanic), age, smoking, obesity, area deprivation index, other DMARD use, RF status, anti-CCP status, and practice type. Longitudinal targeted maximum likelihood estimation estimated the average treatment effect (ATE) of cumulative TNFi vs. non-TNFi use over a 12-month period on CDAl score among the entire population and across various subgroups based on demographic and clinical characteristics, accounting for censoring and time-varying confounding.

Results: Approximately $75 \%$ of patients were female with a mean age of 65.1 (+/- 13.7) years. Sixty percent of patients were white, $8 \%$ black, $2 \%$ Asian, and $30 \%$ other/mixed or unknown race; $6 \%$ were Hispanic. The mean CDAl score at baseline was $11.3(+/-10.7)$. For the overall population, there was no significant difference in disease activity between TNFi and non-TNFi at 12 months $(A T E=0.85,95 \% \mathrm{Cl}-0.26,1.96$; Table 1). Stratified analyses found higher disease activity for TNFi compared to non-TNFi among patients of Black and Asian race, non-Hispanic ethnicity, and female sex. Among Black race patients, TNFi use was associated with a 6.08 point higher CDAl score compared to nonTNFi use $(95 \% \mathrm{Cl} 1.99,10.17)$. In contrast, in Hispanic/Latino ethnicity patients, TNFi use was associated with a lower CDAl score compared to non-TNFi use (ATE $=-2.64,95 \% \mathrm{Cl}-3.99,-1.30$ ).

Table 1. Average treatment effect (ATE) of cumulative TNFi vs. non-TNFi use at 12-months on CDAl score in patients with RA

\begin{tabular}{lccc}
\hline & TNFi & Non-TNFi & ATE $(95 \%$ Cl) \\
\hline Overall $(n=16,448)$ & 8.84 & 7.99 & $0.85(-0.26,1.96)$ \\
Race & & & \\
$\quad$ White $(n=9,814)$ & 8.24 & 6.81 & $1.42(0.03,2.81)^{*}$ \\
$\quad$ Black $(n=1,358)$ & 13.91 & 7.83 & $6.08(1.99,10.17)^{*}$ \\
$\quad$ Asian $(n=301)$ & 6.54 & 2.74 & $3.80(2.93,4.67)^{\star}$ \\
Ethnicity & & & \\
$\quad$ Non-Hispanic $(n=14,216)$ & 8.92 & 7.63 & $1.29(0.08,2.51)^{*}$ \\
$\quad$ Hispanic $(n=938)$ & 5.69 & 8.33 & $-2.64(-3.99,-1.30)^{*}$ \\
Sex & & & \\
$\quad$ Female $(n=12,527)$ & 8.98 & 7.47 & $1.51(0.31,2.72)^{*}$ \\
$\quad$ Male $(n=3,921)$ & 8.57 & 9.49 & $-0.92(-3.42,1.58)$ \\
${ }^{*} P<0.05$ & & &
\end{tabular}

Conclusion: Results from this RCT simulation study suggest that non-TNFi may have an important role as first-line agents in the treatment of Black and Asian patients, but not Hispanic patients. These novel findings fill gaps where RCTs have not been conducted, highlight the need for inclusion of diverse populations in future trials, and have the potential to lead to a more personalized approach to rheumatologic care.

\section{References:}

Disclosure of Interests: Milena Gianfrancesco: None declared, Jing Li: None declared, Michael Evans: None declared, Maya Petersen: None declared, Gabriela Schmajuk: None declared, Jinoos Yazdany Consultant of: Eli Lilly and Astra 
Zeneca, unrelated to this project., Grant/research support from: Gilead, unrelated to this project.

DOI: 10.1136/annrheumdis-2021-eular.1032

\section{OP0118 EFFECT OF WITHDRAWING ETANERCEPT OR METHOTREXATE ON PATIENT-REPORTED OUTCOMES IN RHEUMATOID ARTHRITIS PATIENTS IN REMISSION ON COMBINATION THERAPY: RESULTS FROM THE SEAM-RA TRIAL}

J. Curtis ${ }^{1}$, E. Karis ${ }^{2}$, V. Bykerk ${ }^{3}$, G. Kricorian ${ }^{4}$, P. Yen ${ }^{5}$, P. Emery ${ }^{6}$, P. Haraoui ${ }^{7}$, D. Collier ${ }^{4}$, B. Stolshek ${ }^{8} .{ }^{1}$ University of Alabama at Birmingham, Division of Clinical Immunology and Rheumatology, Birmingham, United States of America; ${ }^{2}$ Amgen Inc, Global Development, California, United States of America: ${ }^{3}$ Hospital for Special Surgery, Department of Rheumatology, New York, United States of America; ${ }^{4}$ Amgen Inc, Global Medical, California, United States of America: ${ }^{5}$ Amgen Inc, Global Biostatistical Science, California, United States of America; ${ }^{6}$ Leeds National Institute for Health Research, Biomedical Research Center at Leeds Teaching Hospitals Trust, LIRMM Leeds University, Division of Rheumatic and Musculoskeletal Disease, Leeds, United Kingdom ${ }^{7}$ Rheumatology Institute of Montreal, Department of Medicine, Montreal, Canada; ${ }^{8}$ Amgen Inc, Global Health Economics, California, United States of America

Background: Limited studies have assessed the effect of withdrawal of either methotrexate (MTX) or etanercept (ETN) on patient-reported outcomes (PROs) in rheumatoid arthritis (RA).

Objectives: To evaluate the baseline and change in PROs following withdrawal of MTX or ETN in RA patients with sustained remission receiving combination ETN+MTX.

Methods: Adult patients with RA on ETN+MTX and in remission (SDAl $\leq 3.3$ ) for $\geq 12$ months (including a 24-week, open-label, run-in period) were randomized to a 48-week double-blind period to receive ETN $50 \mathrm{mg}$ weekly $(\mathrm{N}=101)$, oral MTX $10-25 \mathrm{mg}$ weekly $(\mathrm{N}=101)$ or continue $\mathrm{ETN}+\mathrm{MTX}(\mathrm{N}=51)$. The primary endpoint was maintenance of SDAl remission without disease worsening (DW) at week 48 between ETN and MTX groups. Patients who experienced SDAI >11 at any time after randomization, or SDAI $>3.3$ and $\leq 11$ during 2 consecutive or on 3 non-consecutive visits were considered to have DW and resumed ETN+MTX. PROs assessed were patient global assessment of disease activity (PtGA, 0-100 mm), patient joint pain (PtJP, 0-100 mm), Health Assessment Questionnaire-Disability Index (HAQ-DI), and the 36-item short-form health survey (SF-36) component and domain scores. A 2-sample t-test was used to compare the treatment differences between groups. A subgroup analysis for patients with DW was also performed (DW analysis set) and compared PROs between ETN vs MTX arms (ETN+MTX not shown given the small sample size).

Results: Of the 253 patients randomized, 121 (47.8\%) experienced DW and were included in the DW analysis set. Baseline demographics were generally balanced between the 3 treatment groups. Most patients were women (76.3\%), White $(87.0 \%)$, and with a mean age of 55.6 years. The mean (SD) MTX dose was $16.3(4.69) \mathrm{mg}$ and the mean (SD) duration of RA was 10.3 (7.8) years. At week 48, a significantly greater proportion of patients on ETN vs MTX monotherapy maintained SDAI remission $(49.5 \%$ vs $28.7 \%$; $P=0.004)$ after therapy withdrawal. In the overall population, PtGA and PtJP scores were very low at baseline (PtGA-MTX: 4.4, ETN: 4.5, ETN+MTX: 3.5; PtJP-MTX: 4.9, ETN: 5.5, ETN+MTX: 3.5 ) and showed some worsening over the study period in all treatment groups, with a mean change at week 48 ranging from 5.0 to 10.0 units for PtGA and 3.7 to 8.1 units for PtJP. Patients on ETN had less worsening, with a nominally significant treatment difference observed between ETN and MTX monotherapy groups for PtGA at almost all timepoints, and for PtJP at weeks 12 and 36 (Figure). Mean HAQ-DI (MTX: 0.32; ETN: 0.26; ETN+MTX: 0.28) and SF-36 scores (physical component [PCS]-MTX: 52.1, ETN: 52.7, ETN+MTX: 52.3; mental component [MCS]-MTX: 55.5, ETN: 55.8, ETN+MTX: 57.1) at baseline show that patients had low disability and excellent health-related quality of life compared with normative values for the general non-RA population. HAQ-DI scores were well maintained at weeks 24 and 48 (change from baseline at week 48-MTX: 0.14; ETN: 0.15; ETN+MTX: 0.21). The SF-36 PCS, MCS, and domain scores decreased minimally from baseline with treatment differences that were not nominally significant between groups. Among patients with DW during the study, those on ETN showed less PtGA and PtJP worsening from baseline than those on MTX at weeks 12, 36, and 48 (Figure). Other PROs (HAQ-DI [change from baseline at week 24-ETN: 0.34; MTX: 0.21; at week 48-ETN: 0.15; MTX: $0.15]$, SF-36 PCS, MCS, and domain scores) showed a similar degree of worsening in both the MTX and ETN arms.

Conclusion: In patients with sustained SDAI remission on ETN+MTX, mental and physical health as measured by SF-36 was comparable with that of the non-RA population. Withdrawal of ETN (MTX monotherapy) resulted in a greater worsening of PtGA and PtJP than withdrawal of MTX (ETN monotherapy), and patients on ETN monotherapy restored these scores close to baseline towards the end of the treatment period. These findings demonstrate that ETN monotherapy has a greater effect on maintaining overall patient assessment of disease and joint pain compared with MTX monotherapy.
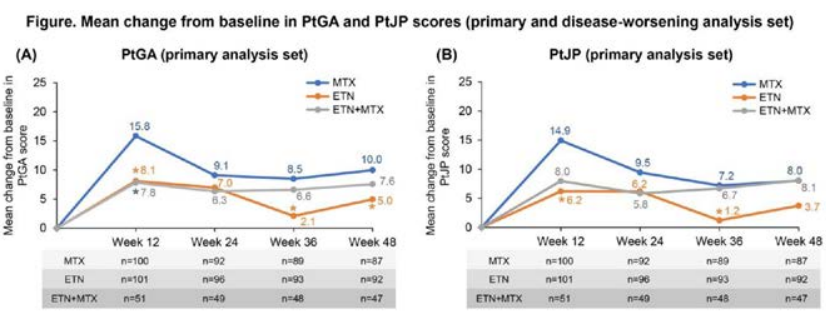

(C) PtGA (disease-worsening analysis set)

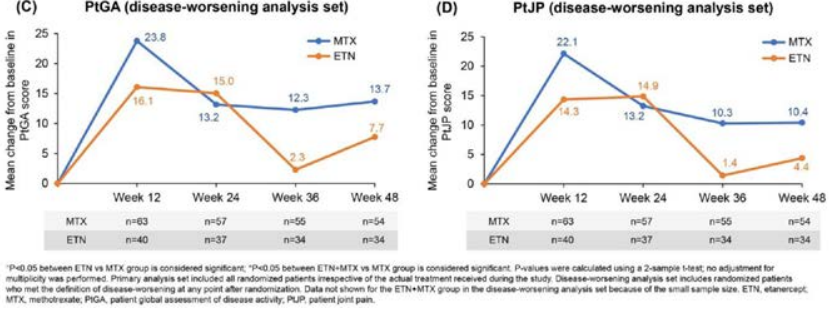

Disclosure of Interests: Jeffrey Curtis Speakers bureau: AbbVie, BMS, Gilead, Lilly, Novartis, Sanofi, Scipher, Amgen, Corrona, Janssen, Myriad, and Pfizer, Consultant of: AbbVie, BMS, Gilead, Lilly, Novartis, Sanofi, Scipher, Amgen, Corrona, Janssen, Myriad, and Pfizer, Grant/research support from: AbbVie, BMS, Gilead, Lilly, Novartis, Sanofi, Scipher, Amgen, Corrona, Janssen, Myriad, and Pfizer, Elaine Karis Shareholder of: Amgen Inc., Employee of: Amgen Inc., Vivian Bykerk Speakers bureau: Amgen, BMS, Gilead, Pfizer, Sanofi-Genzyme/Regeneron, Scipher Medicine, and UCB., Consultant of: Amgen, BMS, Gilead, Pfizer, Sanofi-Genzyme/Regeneron, Scipher Medicine, and UCB. Grant/research support from: Amgen and Novartis, Greg Kricorian Shareholde of: Amgen Inc., Employee of: Amgen Inc., Priscilla Yen Shareholder of: Amgen Inc., Employee of: Amgen Inc., Paul Emery Speakers bureau: AbbVie, BMS Celltrion, Gilead, Lilly, MSD, Novartis, Pfizer, Roche, Samsung, Sandoz, and UCB., Consultant of: AbbVie, BMS, Celltrion, Gilead, Lilly, MSD, Novartis, Pfizer Roche, Samsung, Sandoz, and UCB., Paul Haraoui Speakers bureau: AbbVie, Celgene, Janssen, Pfizer, and UCB., Consultant of: AbbVie, Amgen, BMS Celgene, Eli Lilly, Janssen, Merck, Pfizer, Roche, Sandoz, Sanofi-Genzyme, and UCB., Grant/research support from: Roche, AbbVie, Amgen, Merck, and Pfizer, David Collier Shareholder of: Amgen Inc., Employee of: Amgen Inc., Brad Stolshek Shareholder of: Amgen Inc., Employee of: Amgen Inc. DOI: 10.1136/annrheumdis-2021-eular. 1863

\section{OP0119 \\ SHOULD WE USE BIODMARDS IN FIRST INTENTION IN EARLY RHEUMATOID ARTHRITIS?: RESULTS AT 5 YEARS FROM THE ERA LOUVAIN BRUSSELS COHORT}

E. Sapart ${ }^{1}$, T. Sokolova ${ }^{1}$, S. De Montjoye ${ }^{1}$, S. Dierckx ${ }^{2}$, A. Nzeusseu Toukap ${ }^{1}$, A. Avramovska ${ }^{1}$, L. Meric de Bellefon ${ }^{1}$, P. Durez ${ }^{1} .{ }^{1}$ Cliniques Universitaires Saint-Luc - Université catholique de Louvain (UCL) - Institut de Recherche Expérimentale et Clinique (IREC), Rheumatology, Brussels, Belgium; ${ }^{2} \mathrm{CHU}$ Mont-Godinne, Rheumatology, Mont-Godinne, Belgium

Background: Early effective treatment has led to major improvements in patients with rheumatoid arthritis (ERA). Low disease activity and remission are achieved earlier and in higher frequency when the initial treatment in rheumatoid arthritis includes a combination of methotrexate (MTX) with a bDMARD compared to MTX alone.

Objectives: The aim of this study is to retrospectively analyse and compare the benefit of a treatment with methotrexate (MTX) alone or combined with a bDMARD as an induction therapy during 5 years of follow-up in early rheumatoid arthritis (ERA) patients.

Methods: We included ERA patients from the UCLouvain Brussels cohort who met the ACR/EULAR 2010 classification criteria and were naïve to DMARDs. Treatments were initiated based on the decision of a senior rheumatologist bDMARDs induction therapy was usually limited to 6 or 12 months. We collected patient characteristics at baseline and clinical response was analysed at 6 months, 1 year, 3 years and 5 years.

Results: Data from 470 eligible ERA patients were collected. The average age of the population is 48.9 years; $70.5 \%$ of the patients are women; $27.3 \%$ are smokers and $68.8 \%$ are positive for anti-citrullinated protein antibody (ACPA). 